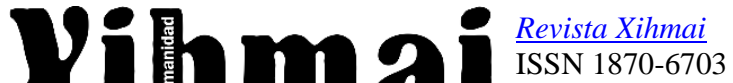 Universidad la Salle Pachuca http://doi.org/10.37646/xihmai.v16i31.519
}

\section{LO SEXUAL Y LA SEXUALIDAD EN EL PSICOANÁLISIS DE JEAN LAPLANCHE}

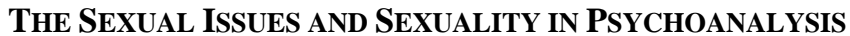
OF JEAN LAPLANCHE

Miguel Ángel Medina Martínez

\section{Nota sobre el autor:}

Maestro en Ciencias de la Educación (Docencia y Gestión) por la Universidad del Valle de México. Especialidad otorgada por la participación en el Programa Hubert H. Humphrey sobre Prevención y Tratamiento del Abuso de Drogas en Johns Hopkins University. Especialidad en Psicoanálisis y Grupos Operativos en la Escuela Interdisciplinaria de Aprendizaje y Comunicación Grupal. Licenciado en Psicología Clínica por la Universidad Iberoamericana.

Esta investigación fue financiada con recursos del autor. El autor no tiene ningún conflicto de interés al haber hecho esta investigación.

Remita cualquier duda o comentario sobre este artículo al siguiente correo electrónico: medmar45@gmail.com

Recibido: 23/11/2020 Corregido: 16/03/2021 Aceptado: 1/04/2021

Copyright (c) 2021 Miguel Ángel Medina Martínez. Este texto está protegido por una licencia CreativeCommons 4.0. 
Xihmai 208 
Lo sexual y la sexualidad en el psicoanálisis de Jean Laplanche Revista Xihmai XVI (31), 207-226, enero-junio 2021

\title{
LO SEXUAL Y LA SEXUALIDAD EN EL PSICOANÁLISIS \\ DE JEAN LAPLANCHE
}

\section{The SeXual ISSUES AND SEXUALITY IN PSYChoANAlysis \\ OF JEAN LAPLANCHE}

\section{Resumen}

Actualmente, mucho se ha escrito sobre la sexualidad desde distintas perspectivas que ofrecen la anatomía, la fisiología y, ahora, la sexología. Este texto aborda una serie de precisiones en torno a las nociones de lo sexual y la sexualidad desde el pensamiento freudiano, a partir de la relectura y desarrollos que, a lo largo de su obra, hiciera el psicoanalista francés Jean Laplanche. Contrariamente a lo que comúnmente se piensa desde las ciencias naturales, lo sexual no puede seguir siendo restringido exclusivamente a la sexualidad genital o coital, y tampoco está determinada por lo biológico sino por lo psíquico-cultural, entendida como todo aquello que tiene que ver con el placer.

Palabras Clave: Sexo, sexual, sexualidad, placer, sexualidad genital, psicoanálisis, instinto, pulsión, metábola, significante enigmático, seducción, autoconservación, fantasías parentales, seducción generalizada.

\begin{abstract}
Today, much has been written about sexuality from different perspectives offered by anatomy, physiology and now, sexology. This text addresses a series of details about the notions of sexuality and sexuality from Freudian thought, based on the rereading and developments that, throughout his work, the French psychoanalyst Jean Laplanche made. Contrary to what is commonly thought from the natural sciences, the sexual cannot continue to be restricted exclusively to genital or coital sexuality, and it is not determined by the biological but by the psychic-cultural, understood as everything that has to do with pleasure.
\end{abstract}

Keywords: Sex, sexual, sexuality, pleasure, genital sexuality, psychoanalysis, instinct, drive, metabola, enigmatic significant, seduction, self-conservation, parental fantasies, general seduction.

Las características de la vida humana que afrontamos hoy han cambiado sustancialmente respecto de aquellas en las que vivíamos hace tan sólo unas décadas. El grado de complejización de las actividades humanas que la vida moderna ha traído consigo, ha permeado todos los ámbitos de esta, incrementando los niveles de confusión y distorsionando los de percepción y 
comprensión de la realidad, lo que puede ser observado fehacientemente en el vivir cotidiano. El ansia por elevar a toda costa el status económico de la vida y por conseguir los bienes y servicios sujetos a la oferta y la demanda, ha impregnado y, muchas veces, sustituido los ideales de una vida digna, segura y respetuosa de los demás, de solidaridad, de educación, antaño perseguidos con vehemencia y hoy día tan ignorados e incluso despreciados por la mayoría de la población.

El análisis de algunos fenómenos sociales a los que nos enfrentamos cotidianamente tales como la desigualdad en la distribución de la riqueza (en lo que también ha contribuido el cinismo, la insaciable avidez y la ignorancia -a veces pusilánime, a veces manifiesta- de personajes políticos obcecados por el propio y por el supuesto beneficio de la economía que traerá la incorporación al mercado globalizador, no obstante las contundentes pruebas contradictorias que representa la lacerante pobreza en los países desarrollados y en los no desarrollados de que no se accederá precisamente a la igualdad entre los seres humanos, sino que contribuirá a ensanchar todavía más la brecha existente entre los cada vez menos ricos y los cada vez muchos más pobres, o la preponderancia de actividades - tales como adquisiciones de bienes fútiles, modas absurdas, servicios innecesarios, avidez por las noticias de violencia generalizada - otrora tan banales en la vida humana, se han vuelto tan apabullantes y asfixiantes que dominan y limitan las perspectivas del ser humano, con el consecuente empobrecimiento y vaciamiento de la vida misma que no encuentra en aquello, ni la felicidad prometida ni la plenitud tan ansiada.

Otro elemento típico de los cambios de la época moderna, lo constituye la vertiginosidad de estos y la complejidad que de ello deriva, dejando a veces al sujeto sin la posibilidad de entender y asimilar no sólo la realidad cambiante sino los modos con que tratamos de asirla y comprenderla. Una manera de plantear estos hechos, la propone Silvia Bleichmar (2007) agrupándola en tres categorías: los cambios científicos, las vicisitudes sociales y políticas y los procesos de cambio en la subjetividad -objeto de análisis propio del psicoanálisis-. En este análisis, si bien Bleichmar incluye el campo de la tecnología médica y las así llamadas neurociencias, podríamos añadir que no hay, prácticamente, área humana alguna que no haya sido modificada radicalmente en los últimos años. Este no es un espacio para dar cuenta de todos y cada uno de los cambios que han tenido lugar en las disciplinas científicas. Tal vez, cabría resaltar aquí -en el ámbito específico de la mente Xihmai 210 
humana y el cerebro- los estudios cada vez más precisos, que también han propiciado un avance mucho más fino en el diagnóstico de enfermedades, así como en el diseño y prescripción de nuevos medicamentos en la psicofarmacología.

Por otro lado, se manifiestan cada vez con mayor vehemencia y contundencia ciertas modificaciones personales, familiares y sociales que abren nuevas formas de relación interhumana o suplantan otras existentes y comunes hasta hace muy poco tiempo. Ejemplo de ello, lo constituye la realidad ya contundente de la lucha por el género en lo "trans", "inter" "homo", "queer", "pangénero" y "asexual", por citar algunos. Asimismo, nuevas formas de asociación o relación, como la de los matrimonios gay, o las relaciones del poliamor, en triejas o cuatriejas y la realidad ya, de la crianza de hijos en el seno de este tipo de parejas, lo que, al parecer, restringe y reduce a su mínima expresión la oportunidad para establecer teorizaciones confiables y una práctica desde el psicoanálisis cuyo nacimiento data de fines del siglo XIX, con un ambiente, costumbres, estilo de vida y manifestaciones culturales muy distintas a las que caracterizan nuestro siglo XXI.

Dentro de lo incierto que se vislumbra el futuro, lo que sí es seguro es que nos espera un mundo cada vez más dominado por las máquinas y los robots. En este sentido, Bleichmar (2007) es contundente:" Un futuro robotizado, maquinizado y guiado por el placer inmediato, parece ser el vaticinio más catastrófico". La informática y la mecatrónica prácticamente no dejan de incidir, conforme el tiempo pasa, en cada vez más ámbitos de la vida humana y no humana: la administración, la medicina, la educación, la ingeniería, la fotografía, la criminología, por citar algunos.

Pero lo que más nos debería llenar de preocupación es la ceguera producida por el espejismo que ofrecen algunas disciplinas del espíritu humano basadas en la inmediatez de lo concreto, lo tangible, medible y cuantificable. Teorías y prácticas reduccionistas a lo biológico y lo conductual hacen caso omiso de la complejidad que representan fenómenos humanos tales como la vida y la muerte, la indiferencia y la pasión, la salud mental y la locura (en su doble acepción de psicosis y a-locarse), la soledad y las relaciones humanas (en todas sus formas: la amistad, la pareja, la familia, las masas)... todo ello, dice Èlisabeth Roudinesco (2013) en el prólogo a su libro ¿Por qué el Psicoanálisis?, es lo que conforma la subjetividad del ser humano, misma que ha sido sustituida por un individualismo que somete al ser humano a la fantasía 
de ser libre sin límites, de ser omnipotente, y que lo impele y le refuerza la creencia de poder hacer lo que se le ocurra, con quien, cuando, donde y cuanto se le antoje.

Esta creciente complejización y diversidad de la vida moderna, llevaron a Laplanche (2013) y a Bleichmar (2007) a romper la actitud de la mera repetición de los desarrollos freudianos en una relectura de Freud que permitiera cuestionar y reubicar la extensión y comprensión del pensamiento freudiano, así como a replantear, no sólo elaboraciones en torno a la teoría, sino al accionar mismo de muchos psicoanalistas que prefieren seguir refiriendo a ultranza situaciones humanas al Complejo de Edipo, al Inconsciente o a la Escena Primaria sin reparar en los cuestionamientos que muchas veces implica la turbulencia de los cambios que ha tenido lugar en el imaginario social y en las formas de determinación de la subjetividad humanas. Hoy, más que nunca, resulta demasiado evidente que lo biológico y lo psíquico pertenecen a dos órdenes de derivación totalmente diferentes. Desde distintas perspectivas, mutuamente enriquecedoras, ambos retoman la idea del apuntalamiento freudiano, que demarca justamente la separación entre la autoconservación y la sexualidad.

Intentaré mostrar sumariamente en este espacio, si es posible y de qué manera podría ser sostenible hablar-del, desde y sobre- el psicoanálisis a una sociedad como la nuestra que dista mucho de poder ser descrita en su totalidad en los párrafos anteriores. No es este un espacio para desarrollar y, menos aún para profundizar en la problemática del género y de los fenómenos LGBTTTIQ (más lo que se acumule). Apenas se apuntan algunas consideraciones preliminares que promuevan una reflexión y un serio debate en torno a estos asuntos, en medio del maremágnum de ideas que cotidianamente nos inundan y obnubilan.

Jean Laplanche, cuyos desarrollos han sido todavía poco difundidos y no muy bien aceptados por su rigurosidad científica y por su nivel de crítica al psicoanálisis francés actual (dominado por la vertiente estructuralista lacaniana), inconforme, además, con las traducciones de la obra freudiana, se dio a la tarea de volver a traducir y discutir acaloradamente con singular altura intelectual y en un debate de intensidad fuera de lo común, los más variados puntos de vista acerca de la traducción del alemán en general y del pensamiento de Freud en particular (Laplanche, 2005). Tradujo nuevamente al francés las obras completas de Freud: su lengua, su estilo y su pensamiento con todo un

Xihmai 212 
equipo de filólogos, freudólogos, germanistas, poetas, filósofos y psicoanalistas expertos. Él prácticamente se dio a conocer desde 1966 con la publicación de El Inconsciente: Un Estudio Psicoanalítico escrito juntamente con Serge Leclaire, además, de otro par de libros en colaboración con Jean Bertrand Pontalis, el famoso Diccionario del Psicoanálisis (1967) y Fantasías Originarias, Fantasías de los Orígenes, Orígenes de la Fantasía (1986). Posteriormente, destacó por sus trabajos sobre diversos temas, lo que se hizo patente con la publicación de varios libros entre ellos: Vida y Muerte en Psicoanálisis Laplanche (1970), una serie de seis libros a la que intituló Problemáticas, sobre diversos temas: La Angustia (2000), Castración (2000), La Sublimación (2002), El Inconsciente y el Ello (2006), La Transferencia (1990), y El Aprés coup (2013). Otros títulos destacados son: Entre Seducción e Inspiración: el Hombre (2001), El Extravío Biologizante de la Sexualidad en Freud (1998), Nuevos Fundamentos para el Psicoanálisis (2001), y otras publicaciones que no han sido traducidas aún al español, a través de las cuales desarrolló una serie de novedosos e interesantes planteamientos agudos y críticos, haciendo explotar las propuestas del psicoanálisis ecolálico y acartonado de los freudianos a ultranza, pero también haciendo manifiestas las contradicciones del mismo Freud y estableciendo en su justa dimensión los alcances y los límites reales de los dos psicoanalistas más destacados del pensamiento post-freudiano: Melanie Klein y Jacques Lacan.

Los ejes de análisis del pensamiento crítico laplanchiano son:

- La sexualidad constituida exógenamente, por desfase de lo autoconservativo y no por contigüidad

- La seducción originaria - la seducción generalizada

- La pulsión

- El realismo del inconsciente

- La angustia

- La teoría del aprés coup

- La simbolización

- La sublimación

Las limitaciones de este espacio nos permiten abordar solamente el primer punto: la sexualidad constituida exógenamente, por considerarlo, además, uno de los ejes fundamentales para una comprensión diferente y actual no sólo de la sexualidad, sino de la misma vida humana.

Para comenzar esta tarea, es preciso recordar las tres dimensiones de la concepción originaria de lo que es el psicoanálisis y que el mismo Freud nos 
ofrece en su artículo "Psicoanálisis": en el que sostiene que, "Este es el nombre:

1. De un procedimiento para indagar procesos anímicos difícilmente accesibles por otras vías;

2. De un método de tratamiento de perturbaciones neuróticas, fundado en esa indagación, y

3. De una serie de intelecciones psicológicas, ganadas por ese camino, que han ido coligando una nueva disciplina científica". (Freud, 2012a, p. 231)

No es pues, sólo un método terapéutico, sino primero y ante todo, un método de investigación sobre fenómenos que ningún otro estudio de la mente humana había explorado en su momento y también de una serie de conceptos que se integrarían en la nueva ciencia del psicoanálisis. Entre estos nuevos conceptos, se encuentra el de la sexualidad, que tiene un hilo conductor abordado en Tres Ensayos de una Teoría Sexual, obra que mostró en sucesivas ediciones en $1905,1910,1915,1920$ y 1924-1925.

El plan de esta obra de Freud está dividido en tres partes: las aberraciones sexuales, la sexualidad infantil y las transformaciones de la pubertad. Según Laplanche, esta obra tiene varios planos en los cuales puede ser ordenada: uno heurístico "[...] sobre la génesis del descubrimiento psicoanalítico, otro, el polémico cuyo propósito es destruir la concepción popular de la sexualidad y el genético en el que investiga los orígenes de la sexualidad en el ser humano". (Laplanche 1992)

Es importante señalar que -para Laplanche- en Freud están perfectamente bien diferenciados los conceptos de instinto y pulsión: Instinkt cuando Freud hace referencia a lo instintivo tal cual aparece en los animales y Trieb pulsión, para referirse a eso que es lo específicamente humano y cuyo representante psíquico lo constituye el deseo y no ya el instinto. Esta diferenciación no fue acatada en las diversas traducciones de la obra freudiana creando niveles de confusión que aún hoy todavía persisten en muchos lectores. Desde esta comprensión, Freud planteará que la sexualidad -entendida como todo aquello que tiene qué ver con el placer y no restringida solamente al placer genital-es el modelo de toda pulsión. Así, no puede haber otro tipo de pulsión más que la pulsión sexual, entendida como la fuerza o la presión que existe en el ser humano para conseguir el placer a través de un objeto específico (real o fantaseado) para ese sujeto. Dicho así, también es casi seguro afirmar que la sexualidad sea la única

Xihmai 214 
pulsión en el verdadero sentido del término. Vale la pena recordar las sucesivas vueltas de espiral que el concepto de pulsión tuvo en Freud: habiendo asumido en primer término que existían las pulsiones de autoconservación y las sexuales, posteriormente afirmará que solamente existen las pulsiones sexuales, a las que dividirá finalmente en: pulsiones de vida y de muerte.

Un concepto freudiano fundamental rescatado por Laplanche es que, en el humano, la vida psíquica o psicosexual está apuntalada en lo biológico: este desarrollo, no quiere decir que la psique surja de ella en una relación de contigüidad, sino en franca ruptura con ella. Es decir, se constituye a partir de los cuidados maternos en las primeras fases de la vida y no por el simple hecho de estar equipado con un sistema nervioso central y con neuronas humanas. Si una máquina robotizada pudiera atender todas las necesidades físicas y hacer subsistir un infante en las condiciones óptimas de clima, alimentación, higiene, etc., de modo que no implicara la instauración de un vínculo intersubjetivo capaz de introducir al bebé en el mundo del placer y los significados, lo más probable es que se lograría constituir un niño feral o un niño autista. Es decir, parece que si no hay una madre (ó cualquiera que ejerza la función materna) que lo pulse y lo sexualice, que lo recubra con sus fantasmas, sus deseos, que le apapache, le dé su calor, le hable y le cante, muy probablemente sólo podríamos aspirar a tener un cuerpo biológico humano, sin eso que lo diferencia del mundo animal, es decir, la cultura. Por eso, la pulsión es un concepto límite entre lo biológico y lo psíquico humano (Laplanche, 1982), que se constituye en una línea de intersección y a la que Freud denominó precisamente como el apuntalamiento, es la línea que une lo biológico con lo psicológico, pero no en una línea de contigüidad, sino donde se gesta algo nuevo y diferente a lo que existía previamente, es decir "[...] hay génesis de algo a partir de otra cosa" (p. 131). Es Freud mismo quien apuntó que,

[...] el chupeteo -tomado como modelo de la sexualidad oral- nos permitió observar los tres caracteres de la sexualidad infantil. Esta se desarrolla apuntalándose en alguna de las funciones corporales de mayor importancia vital, no conoce aún ningún objeto sexual, es autoerótica y su fin está determinado por la actividad de una zona erógena. (2012, p. 165)

Y, Laplanche lo representa gráficamente de la siguiente manera para ejemplificar que -a partir de la estimulación sexual inconsciente por parte de la madre- en las labores de autoconservación se gesta(rá) e-so-nue-vo-que-eslo-se-xual-en-el-ni-ño, no en un movimiento de contigüidad -como se dijo más arriba- sino en uno de ruptura, que dará origen precisamente a la capacidad de experimentar el placer de manera totalmente diferente al 
experimentado por la madre. Es muy importante resaltar que el ofrecimiento de la madre no es directa y conscientemente, lo que entra en el bebé. Laplanche propondrá dos conceptos para comenzar a cercar esta idea de neoproducción psíquica en el niño:

1) El concepto de metábola, que propusiera en La sublimación (2002) y luego desarrollara con mayor amplitud en El inconsciente y el Ello (2006) como algo que viene de fuera pero que requiere un procesamiento de metabolización para ser internalizado finalmente y transformado en una pulsión que ya no es la de la madre sino del sujeto incipiente.

2) $\mathrm{Y}$, el concepto de significante enigmático que aparece por vez primera en El Inconsciente y el Ello (2006), también es ampliado en Nuevos fundamentos para el psicoanálisis (1987b) y alude a mensajes no necesaria y únicamente verbales para referirse a la idea de que la madre misma -y con mayor razón el bebé- desconoce lo que está siendo transferido al niño en los cuidados de la autoconservación, toda vez que es inconsciente. De otra suerte, estaríamos hablando del ejercicio de un abuso perverso y patológico de la madre:

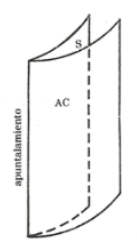

Fig. 1

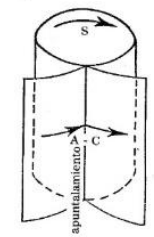

Fig. 2

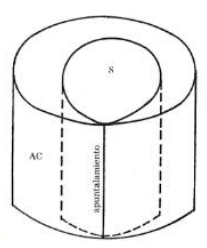

Fig. 3

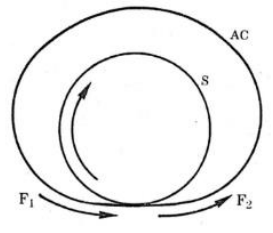

Fig. $4^{1}$

Laplanche (1987a pp. 162-164 y 1982 p. 135) utiliza las cuatro figuras que se muestran para explicar gráficamente este proceso de gestación de lo sexual y, por ende, de lo psíquico propiamente humano. Así, en lo sucesivo, cuando el plano de la autoconservación se altere, o se mueva, repercutirá o se mostrará de otra manera sobre el sexual o viceversa, es decir, que toda actividad adaptativa (como el comer, el ver, la defensa propia o el aseo) puede ser sustentada por una actividad sexual (entendida como obtener placer, evitar el displacer) o, toda actividad sexual puede derivar o provenir del plano

\footnotetext{
${ }^{1}$ Las figuras 1, 3 y 4 fueron tomadas de Laplanche (1987a), pp.162 a 164. La figura 2 de la Revista Trabajo del Psicoanálisis Vol. 1, Núm. 2, 1982, p. 135
}

Xihmai 216 
autoconservativo. Es decir, tanto el orden de la adaptación como la actividad sexual, tienen un punto de coincidencia -Laplanche (1987a) dice tangencialmente (véase más arriba, la noción de apuntalamiento) y en ocasiones- porque tampoco son totalmente coincidentes... Los dos planos se encuentran "en una relación de articulación, pero también de génesis" (p. 163). Ambos quedarán vinculados de manera confusa pero inevitable de tal suerte que, si algo "se mueve" en uno, repercutirá en el otro plano, generando así un movimiento de ida y vuelta, aunque cabe decir que en un sentido diferente -adviértase la flecha interna (lo sexual, pulsiones de vida y muerte)girando en sentido contrario a la externa (lo biológico, los intereses) para ilustrar un elemento totalmente diferenciado de la autoconservación.

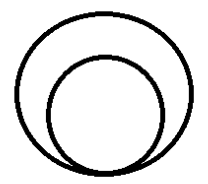

Fig. $5^{2}$ (El pliegue del diedro visto desde arriba).

Esto es precisamente lo que marca, entre otras cosas, también la diferencia entre instinto y pulsión: el instinto sería innato y estaría desde el principio de la vida en el equipamiento biológico del niño (si lo tuviera); acá, hay un surgimiento de lo sexual (pulsión, obtención de placer, evitación del displacer) a partir de los movimientos que la madre realiza desde lo conservativobiológico (es necesario insistir en que esto es operado por la madre y no por el bebé para esclarecer que lo sexual se instaura desde afuera y no es producto de la maduración fisiológica del niño) mediante el vínculo intersubjetivo que inaugura aquella. La reflexión laplanchiana va todavía más allá y conduce a resaltar aún más la dimensión y trascendencia del descubrimiento freudiano del apuntalamiento en el sentido de que ambos planos no existen totalmente independientes uno del otro, sino al contrario: “... uno y otro por igual pueden ser llamados tanto psíquicos como somáticos: [pues)] lo sexual no es más psíquico ni la autoconservación más somática; [es decir] uno y otra son aspectos globales de un funcionamiento que tiene un sentido" (Laplanche, 1987b, p. 145). Siendo igualmente psíquicos e igualmente somáticos uno y otro, se articularán - una vez constituido el aparato psíquico en el ser humano${ }^{2}$ Laplance, J. (1987a). La cubeta. Trascendencia de la Transferencia. Problemáticas V. p. 164.
Amorrortu Editores. 
según para mantener el equilibrio energético o para llevar la tensión o excitación al punto cero), (Laplanche, 1987a).

No existe un paralelismo entre la autoconservación y la sexualidad. Si funcionaran paralelamente, no habría puntos de contacto, ni se generarían los movimientos aludidos anteriormente de ida y vuelta. (Cabría aquí preguntarse también si este modelo podría ser aplicado al supuesto paralelismo existente entre lo cerebral y lo psíquico). Laplanche precisa aún más las interrelaciones entre lo sexual y lo autoconservativo: “...en ciertos puntos hay producción o reproducción de lo sexual. Producción de lo sexual a partir de acontecimientos o de procesos situados en la infancia, pero también producción o desencadenamiento de los sexual a partir de la vida diurna, cuando se trata del modelo del sueño..." (Laplanche 1987a, p. 165)

Un análisis más profundo del concepto de la sexualidad en Freud, revela que su descubrimiento y ubicación epistemológica viene a romper totalmente con la concepción tenida hasta ese momento. Al decir de Laplanche, la sexualidad es ampliada en comprensión pues Freud deja de restringirse única y exclusivamente a la vida genital, deja de ser reducida sólo a las actividades que se relacionan con el coito y se amplía también en extensión porque ya no sólo es válido aplicarla a la vida del joven o del adulto, sino al ser humano prácticamente desde el nacimiento, aunque en la misma concepción freudiana la vida sexual no se constituye por derivación de la biología, (Laplanche 2001b).

Esta idea "desde el nacimiento" merece no olvidar una precisión: Freud y, posteriormente, Laplanche nunca dejan de referirse al vínculo intersubjetivo que la madre establece con el bebé a través de las actividades de conservación que este requiere (amamantamiento, limpieza y cuidados corporales, por ejemplo) para vivir. Estas actividades implican un contacto físico con toda la piel del bebé y también con zonas muy específicas las que, en el pensamiento de Laplanche (2001b), se prestan a revestirse de un carácter erogenizante:

Estas zonas atraen, por lo tanto, las primeras maniobras erógenas de parte del adulto. Hecho más importante aún, si se hace entrar en juego la subjetividad del primer 'compañero', estas zonas nuclean las fantasías parentales y ante todo, las fantasías maternas, de modo que podría decirse, en un sentido apenas metafórico, que constituyen los puntos por los que se introduce en el niño ese cuerpo extraño interno que es, en realidad, la excitación sexual. (p.37)

Xihmai 218 
Las implicaciones de esta nueva concepción quizás aún no han sido suficientemente exploradas y comprendidas en su justa dimensión, dado que una vez introducido ese cuerpo extraño que está afuera- el placer constituirá el leitmotiv -consciente o inconscientemente- en la vida del ser humano. Es decir, no hay actividad humana alguna que no tenga que ver con la consecución del placer y la evitación del displacer: lo que hacemos y haremos a lo largo de la vida, será únicamente con la finalidad de obtenerlo y desechar el displacer. Esto quiere decir entonces que aún las actividades que implican una obligación o sacrificio, pueden corresponder a un gusto o a un mayor bien propio, ¡incluso en la procuración del bien ajeno o en el amor altruista! Es lo único que podría explicar tantas relaciones masoquistas tan dolorosas que se gestan en algunos seres humanos cuyo placer inconsciente les hace soportar altos niveles de dolor enquistado en el amor consciente que profesan al otro, hasta que se percatan de lo que -sin saber- estaban satisfaciendo o hasta que llegan al hartazgo y en el exabrupto rompen con el esquema en que se encontraban insertos (en la búsqueda y consecución de un mejor y mayor placer y bienestar).

Una salvedad: el pensamiento freudiano no ha estado exento de interpretaciones reduccionistas. Así, por ejemplo, durante mucho tiempo, ora por las condiciones reivindicatorias y tendientes a la liberación de todo lo que sonara a represión sexual, ora por fallas en la traducción indistinta que se hizo de Trieb y de Instinkt como instinto, derivó en el planteamiento de que Freud siempre se refería al sexo como algo instintivo y no a lo sexual como lo que tiene que ver con el placer en general y no necesariamente genital o coital. Por estos malentendidos se afirmaba que la teoría freudiana era un simple y llano pansexualismo. Quizá alguien podría argumentar aún hoy en día, con la precisión antes referida, que la teoría sigue siendo pansexualista o panhedonista al, ahora, estar relacionado todo genéricamente al placer. Y, de nuevo, Laplanche puntualiza este punto con una claridad extraordinaria: no es lo mismo decir que todo es sexual (pansexualismo), a sostener que -en todohay algo que es sexual, pues de cualquier manera, todo lo que afrontamos o emprendemos los seres humanos -aún lo más sublime- puede ser placentero o displacentero, y no necesariamente genital.

Aunque hay que decirlo: Freud mismo dio pie a este tipo de desarrollos pansexualistas al formular en sus obras Neuropsicosis de Defensa (1894) y Nuevas Observaciones sobre Neuropsicosis de Defensa (1896), en las que, simultáneamente con su planteamiento sobre lo psíquico, las representaciones, lo simbólico, la importancia del recuerdo reprimido, desarrolla paralelamente 
otra línea de pensamiento en la cual ni la defensa, ni el sentido metafórico, ni el recuerdo cobraban importancia, sino que la angustia se relacionaba con la falta o inadecuada descarga de energía sexual (genital). Sin embargo, este planteamiento jamás volvió a ser objeto de sus desarrollos, y sí, el resto de su vida y de su obra la consagró a desplegar en su máxima expresión la teoría sobre el psiquismo como algo totalmente diferente de lo biológico y sobre la vida representativa, metafórica y simbólica del ser humano.

Otro de los ejes del pensamiento laplanchiano, es la teoría de la seducción generalizada: en los orígenes del pensamiento psicoanalítico, Freud buscó detectivescamente el origen de la neurosis en un evento traumático que había tenido lugar en la infancia; es decir, tenía que dar con el adulto que había seducido o abusado del menor en cualquiera de las formas, y lo hizo durante un largo tiempo con sus histéricas, hasta que se percató de que la mayoría de ellas, ¡le mentían! (recuerdo encubridor). En ese momento, cambió totalmente su perspectiva y esbozó otra línea de pensamiento, en la que planteó: “....la fantasía toca el terreno de la realidad efectiva, pues fue efectivamente la madre quien, en la realización de los cuidados corporales, provocó necesariamente y tal vez despertó por primera vez sensaciones de placer en el órgano genital”. (Freud, 2012)

Según Laplanche, esta línea de reflexión adolece en Freud de muchas cosas: nunca la aplicó a toda la humanidad, no extendió tampoco la idea de la seducción a la idea de la sexualidad en general, tampoco puso en juego el inconsciente de la madre, ni resituó a la seducción en el conjunto teórico de su pensamiento. En los desarrollos de Laplanche, la madre no es un organismo puramente centrado sobre la autoconservación. Es ella la que, a través del amamantamiento y de los cuidados del aseo del niño, "pervierte" el orden de la necesidad (en el sentido etimológico del término: "llevar por otro camino" que no es el de la autoconservación, sino el sexual). Es la madre la que comenzará a introducir lo sexual (mundo del placer) en el vínculo intersubjetivo que arma ella con su bebé al amamantarlo o al limpiarle la colita. Se refuerza así, la idea de que la sexualidad no es algo inherente a la maduración biológica, sino que es introducida exógenamente desde la sexualidad de la propia madre. Nuevamente, el así llamado instinto sexual en el humano, no lo es tal, dado que aparece muy tardíamente en éste: es hasta la pubertad, con la maduración de los sistemas genitales, que hace francamente su aparición. En el niño -al nacer- no existe ni la disposición ni la aptitud para el coito. Y, además, cuando esto aparece, ya la psique humana ha estado

Xihmai 220 
habitada por otros modos de funcionamiento sexual (en sentido amplio) lo que se reorganizará alrededor de lo sexual genital y ejercerá su influencia definitiva en las formas como se obtendrá el placer de la vida.

A las labores de amamantamiento y cuidados del niño a través de las cuales la madre introduce al bebé al mundo del placer, Laplanche, lo llama directamente seducción. Seducción precoz, vehiculizada a través de las atenciones corporales que la madre realiza a su hijo para que este viva. Como se señaló más arriba, el cachorro humano es el menos dotado para las labores de supervivencia, por ello, depende total y absolutamente de las atenciones y cuidados del adulto. Atenciones y cuidados que inevitablemente se intrincarán con los fantasmas sexuales inconscientes y preconscientes del adulto y se transmitirán al niño de la crianza de una manera inconsciente, pues el sujeto adulto está atravesado por la escisión que le implica la constitución de su aparato psíquico ya formado. Es esta una relación muy curiosa de intercambio de mensajes que se establece entre el adulto y el niño, pues ni el emisor adulto sabe qué mensaje está enviando, ni el niño tiene los elementos necesarios todavía para poderlo interpretar. Es una relación de actividad y pasividad, según Laplanche, entre un psiquismo parental mucho más rico y formado que el -apenas incipiente- de un niño.

Al niño, le llegarán - dice Laplanche- como mensajes enigmáticos, que deberá comenzar a descifrar, a traducir, a codificar. Baste tomar como ejemplo de ello la así llamada "escena primaria" del coito parental, que implica la presencia de un mensaje, del cual ni el emisor ni el receptor pueden ser específicamente conscientes. En dichos mensajes, se insinúan -sin saberlo el propio emisorretoños de su inconsciente. Esto enigmático, intuido por el niño y fuente necesaria de malestar, induce la búsqueda de una mejor comprensión de lo que le sucede. Es algo incomprensible para el niño, tanto si sucede desde lo real, como en el orden de lo fantaseado, pues para que se registre su operación, dice Laplanche, que siempre se trata de representaciones, a partir de algo que sucedió en lo real. Pero es este nivel de incomprensión, lo que pondrá en marcha el movimiento constitutivo de lo típicamente humano: su posibilidad de acceder a su propio placer, a sus propios significados, ya desgajados de aquellos que otrora le proporcionara su madre. Entonces, la sexualidad es algo que vino de afuera, del otro y que se convierte en algo propio... y, además, es algo a lo que se nos empujó, pero después será aquello que nos empujará a vivir la vida disfrutando de y en ella... y, también, tiene que ver con las 
representaciones, aunque finalmente el placer sólo pueda ser sentido en el cuerpo.

En este orden de cosas, Freud derivará también en la pesquisa del inconsciente, que nos lleva a la búsqueda del placer, aun cuando no seamos conscientes de ello y, en ello estribará la disyuntiva a la que tendrá que enfrentarse el ser humano durante toda su vida, una vez que se constituya su aparato psíquico: perseguir la consecución del placer que construye versus aquel otro que destruye (a sí mismo y a los demás).

\section{A manera de conclusiones}

Es importante señalar que no hay ciencia que abarque en su totalidad lo que es el fenómeno humano por el alto grado de complejidad que éste implica. Pero de entre las opciones científicas de que se dispone, no cabe la menor duda: el psicoanálisis sigue siendo una herramienta fundamental para su comprensión, toda vez que es necesario despojarse de marcos teóricos que por simplistas o por reduccionistas o por el grado de eclecticismo en que se han visto inmersos, redundan finalmente en la esterilidad.

Un psicoanálisis para el siglo XXI implica sacarlo de una vez por todas de la momificación externa en que se le ha metido cuando se afirma de él que es una teoría que todo lo explica por lo sexual genital. Pero también, desde el corpus teórico mismo del psicoanálisis, pues los conceptos necesitan ser retrabajados a la luz de los cada vez más nuevos descubrimientos científicos de manera que no pierdan la coherencia intrateórica, ni la riqueza de sus postulados, así como que no pueda ser reemplazado por ninguna otra práctica o teoría del orden que sea, respecto al conjunto de fenómenos que se propone abarcar.

El psicoanálisis sí es una teoría sobre la sexualidad humana pero entendida como introducción al mundo del placer en general. Hoy más que nunca se ha comprobado que LA MISMA SEXUALIDAD GENITAL NO TIENE COMO FIN ÚLTIMO Y EXCLUSIVO LA PROCREACIÓN, SINO TAMBIÉN -Y QUIZÁS AHORA, SOBRE TODO- EL PLACER. Esto da al traste con perspectivas atávicas que sometieron y reprimieron durante tanto tiempo al ser humano, particularmente a las mujeres.

En este sigo XXI ya se puede afirmar que la sexualidad humana está impregnada del placer, por lo que se deberá aprender a ejercerla sin atentar

Xihmai 222 
contra sí mismo y sin afectar negativamente al otro humano en cualquiera de sus formas. Este hecho no viene a dar por tierra con el psicoanálisis sino a confirmar el anticipo genial de su descubrimiento.

Asimismo, es pertinente pues, volver a recordar hasta el cansancio, que el psicoanálisis, antes que un tratamiento, antes que una teoría, es un método de abordaje, por un lado y, de verificación por el otro. El texto y el contexto del paciente tienen agujeros que es preciso llenar. Pero también tiene un tinte de rompecabezas: falta una pieza que es necesario encontrar para llenar el agujero que está sin ocupar. No de una manera a ultranza, dando cabida a la hermenéutica interpretante desde afuera, sino descubriendo junto con el paciente aquello que ha permanecido sin traducir y que sigue operando desde el inconsciente.

Cabe señalar, asimismo, el hecho de no perder de vista que el psicoanálisis trabaja con otro orden de realidad, distinto de la realidad material y diferente de la realidad cognitiva. Se trata de la realidad psíquica que, desde ninguna perspectiva, tiene relación de contigüidad con el orden de lo biológico. Y, es necesario buscar y encontrar entonces, en ese otro orden de determinaciones, las vicisitudes por las que ha atravesado un sujeto a lo largo de su vida, es decir, descubrir aquello que se ha constituido en el aparato psíquico de una persona para percibir el mundo y para operar en él como lo hace.

Continuar avanzando en el siglo XXI dignamente en concordancia con sus orígenes, cabe decir junto al pensamiento más avanzado de nuestra época, es lo que se espera del psicoanálisis en este tiempo. En este sentido, propuestas como la de Jean Laplanche, Elisabeth Roudinesco y Silvia Bleichmar, son urgentes y necesarias por su fecundidad y la agudeza crítica que les caracteriza tanto con respecto al mismo Freud como a sus seguidores. A partir de allí, podemos imaginar y fantasear respecto al psicoanalista del futuro y, sobre todo, a su existencia misma.

Parafraseando a Silvia Bleichmar, habrá que ver si los planteamientos del psicoanálisis tendrán o no un lugar en el siglo XXI, o si serán suplantados por marcos teóricos más prolíficos o si su imposibilidad para enfrentar las nuevas demandas y situaciones humanas vitales del siglo harán que explote o implosione desde el interior, para ser sustituido por los intereses de los poderes económicos y políticos y no por la verdad. 
A poco más de 80 años de la muerte de Freud, aún sigue habiendo muchas resistencias y muchas dificultades para comprender el papel trascendental que tiene la vida inconsciente en el ser humano. Esta es una consecuencia más de la preponderancia actual en los esquemas positivista, neopositivista, empirista y pragmático y que han permeado casi todas las esferas de la vida.

La enseñanza actual en las escuelas de enseñanza básica, media y superior sobre la sexualidad consiste en aprender y saber sobre tres aspectos: 1) La estructura y funciones del sistema sexual reproductor; 2) Las enfermedades de transmisión sexual y 3) Los modos de contracepción. Lo que más se ha acercado a esta temática ha sido la incorporación de temas relativos a las cuestiones de género (aunque todavía desde una perspectiva marcadamente genético-biológica) en algunas instancias y espacios académicos. Si bien esto ha significado un gran avance en la aceptación de la sexualidad, poco o nada se dice acerca de los aspectos psíquicos que entran en juego acerca de la misma, a no ser que haya algo anormal en las manifestaciones de alguna persona. Todavía dista mucho de ser incorporada la dimensión y trascendencia psíquicas, aún cuesta mucho trabajo asumir que la sexualidad, es decir, la posibilidad de extraer placer de la vida y la constitución de la vida psíquica la fundación de la inteligencia, los procesos de pensamiento, la vida afectiva y los comportamientos del ser humano- están determinados, no por lo biológico sino por el vínculo intersubjetivo que se instaure entre la madre y su hijo. Urge comprender e incorporar estos postulados en los esquemas de pensamiento, de referencia y de acción: es tiempo ya de que la fecundidad de las enseñanzas y descubrimientos freudianos en torno a la comprensión de lo sexual y la sexualidad humana deje de estar constreñida atávica y exclusivamente a lo genital y lo coital.

Así, deberemos tener bien claros los núcleos de verdad que el psicoanálisis ofrece y aplicarlos en los nuevos contextos de la vida humana asumiendo la trascendental importancia que el placer tiene no sólo en la consecución de la siempre ansiada felicidad sino en la obstaculización inconsciente de la misma. Porque sin saberlo, podría estarse satisfaciendo otro deseo u obteniendo otro placer distinto completamente del deseo consciente. Esto puede ayudar a comprender porqué si nadie persigue conscientemente algo que le pueda infringir algún daño severo o le cause la misma muerte, se consuma. O porqué se tienen pensamientos, actitudes y conductas bizarras, crueles y destructivas hacia el entorno natural, en las relaciones humanas y hacia otros seres humanos... Dicho de otro modo, la realidad y la reflexión teórica nos Xihmai 224 
impondrán también la obligación de repensar creativa y fecundamente los modos de concebir - desde el psicoanálisis- el ejercicio pleno y satisfactorio de la genitalidad, entendida como algo que está mucho más allá de la concreción o posibilidad de obtener o no uno o múltiples orgasmos.

\section{REFERENCIAS}

Bleichmar, S. (2007). El Legado del Psicoanálisis. En Carpintero, E. (compilador) Un Psicoanalista en el 2050. Editorial Topía.

Freud, S. (2012a). Psicoanálisis Obras Completas. Tomo XVIII. Amorrortu Editores.

Freud, S. (2012b). Tres ensayos de teoría sexual. Obras Completas. Tomo VII. Amorrortu Editores.

Freud, S. (2012c). Nuevas Conferencias de Introducción al Psicoanálisis. Obras Completas. Tomo XXII. Amorrortu Editores.

Laplanche, J. (1982). El psicoanalista y su cubeta. Revista Trabajo del Psicoanálisis, Vol. 1 Núm. 2, pp. 125-144.

Laplanche, J. (1987a). La Cubeta. Trascendencia de la Transferencia. Problemáticas V. Amorrortu Editores.

Laplanche, J. (1987b). Nuevos Fundamentos para el Psicoanálisis. La Seducción Originaria. Amorrortu Editores.

Laplanche, J. (1992). Vida y Muerte en Psicoanálisis. Amorrortu Editores.

Laplanche, J. (1998). El Extravío Biologizante en Freud. Amorrortu Editores.

Laplanche, J. (2000a). La Angustia. Problemáticas I. Amorrortu Editores.

Laplanche, J. (2000b). Castración. Simbolizaciones. Problemáticas II. Amorrortu Editores.

Laplanche, J. (2001a). Entre Seducción e Inspiración: el Hombre. Amorrortu Editores.

Laplanche, J. (2001b). Vida y Muerte en Psicoanálisis. Amorrortu Editores.

Laplanche, J. (2002). La Sublimación. Problemáticas III. Amorrortu Editores. 
Lo sexual y la sexualidad en el psicoanálisis de Jean Laplanche Revista Xihmai XVI (31), 207-226, enero-junio 2021

Laplanche, J. (2006). El Inconsciente y el Ello. Problemáticas IV. Amorrortu Editores.

Laplanche, J. (2013.) El Après Coup. Problemáticas VI. Amorrortu Editores.

Laplanche, J. (2017). Fantasías Originarias, Fantasías de los Orígenes, Orígenes de la Fantasía. Gedisa Mexicana.

Laplanche, J.; Cotet, P. \& Rey, J.M. (2005). Traducir a Freud. Nueva Visión.

Laplanche, J. \& Leclaire, S. (1970). El Inconsciente. Un Estudio Psicoanalítico. Siglo XXI.

Laplanche, J. \& Pontalis, J.B. (2019). Diccionario de Psicoanálisis. Paidós.

Roudinesco, E. (2013). ¿Por qué el Psicoanálisis? Paidós.

Usted es libre para compartir — copiar y redistribuir el material en cualquier medio o formatoy adaptar el documento — remezclar, transformar y crear a partir del material - para cualquier propósito, incluso para fines comerciales, siempre que cumpla la condición de:

Atribución - Usted debe dar crédito de manera adecuada, brindar un enlace a la licencia, e indicar si se han realizado cambios. Puede hacerlo en cualquier forma razonable, pero no de forma tal que sugiera que usted o su uso tienen el apoyo de la licenciante.

Xihmai 226 